
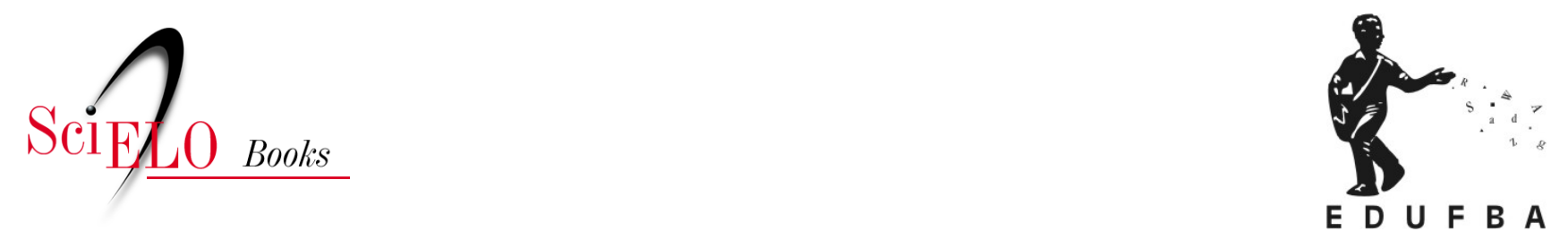

\title{
Agora os meninos precisam saber que coisa de menina também é coisa de menino! Hip-hop feminista?
}

\author{
Rebeca Sobral Freire
}

\section{SciELO Books / SciELO Livros / SciELO Libros}

FREIRE, R.S. Agora os meninos precisam saber que coisa de menina também é coisa de menino! Hip-hop feminista? In: Hip-hop feminista? Convenções de gênero e feminismos no movimento Hiphop soteropolitano [online]. Salvador: EDUFBA/NEIM, 2018. Bahianas collection, n. 20, pp. 163189. ISBN: 978-85-232-1862-1. https://doi.org/10.7476/9788523218621.0007.

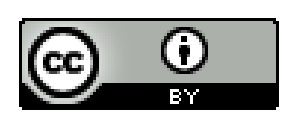

All the contents of this work, except where otherwise noted, is licensed under a Creative Commons Attribution $\underline{4.0 \text { International license. }}$

Todo o conteúdo deste trabalho, exceto quando houver ressalva, é publicado sob a licença Creative Commons Atribição 4.0. 


\section{AGORA OS MENINOS PRECISAM SABER QUE COISA DE MENINA TAMBÉM É COISA DE MENINO! HIP-HOP FEMINISTA?}

Foi apresentada anteriormente a busca de compreender e analisar o contexto em que mulheres jovens entraram em contato com o hip-hop, bem como as motivações e oportunidades para sua inserção nesse Movimento. Foram investigados os elementos e atributos que qualificam o Hip-hop como um movimento de contestação social, refletindo se este é capaz de contestar as convenções de gênero, além de identificar essas convenções dentro do próprio movimento.

O desenvolvimento dessa reflexão trouxe a necessidade de se pensar sobre a possibilidade da existência de um Hip-hop feminista $^{81} \mathrm{em}$ suas possíveis concepções, com vistas a avançar na compreensão acerca do feminismo na sua pluralidade como movimento social, bem como as concepções de feminismo que estão sendo (re)produzidas na prática política dessas jovens mulheres militantes. Aqui há a procura em compreender quais são os possíveis


810 termo "hip-hop feminista" surgiu das conversas nas reuniões de orientação com a professora Dra. Katrine Gines (Vanderbilt University). 
diálogos entre feminismo e hip-hop, a partir das experiências cotidianas em torno de questões de raça, militância e sexualidade dentro do cenário do movimento.

Assim, parte-se das premissas de que, como um movimento social, o Hip-hop dialoga com a cultura política local, ao mesmo tempo em que a desafia, ao afirmar pautas e estratégias políticas de reivindicação de direitos e de combate às desigualdades, como mencionado anteriormente. Retomando o conceito de cultura política proposto por Evelina Dagnino, Sonia Alvarez e Antonio Escobar (2000), é a partir da prática de sua política cultural que esse movimento social dialoga com o modelo hegemônico de cultura política, enfrentando e redefinindo os significados das relações de poder configuradas entre a cultura e a política, conforme as experiências apresentadas nos capítulos antecessores.

A pretensão deste capítulo é de perceber, a partir dessas particularidades, como essa militância desafia e (re)significa, em especial, os movimentos feministas com os quais estão em diálogo, partindo da combinação particular de três gramáticas ${ }^{82}$ políticas: movimento Feminista, movimento Negro e movimento de Juventude.

Deste diálogo entre o feminismo e o hip-hop, na perspectiva das mulheres hip hoppers, resultaram diversas relações a serem observadas. Como vimos no capítulo anterior, o hip-hop tem se constituído como um espaço "potencial” de contestação das convenções de gênero para as mulheres jovens, o que remete ao diálogo possível entre esse movimento e o feminismo. Algumas considerações sobre esse debate se impõem quando colocados, lado

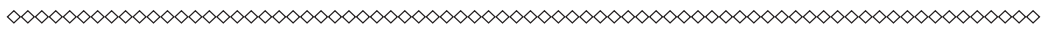

82 A utilização do termo "gramática política" para se referir aos distintos modelos de mobilização política que influenciaram o que procuro denominar como "hip-hop feminista" inspirou-se na análise de Edson Nunes (1997) sobre a gramática política no Brasil. Segundo explicita o autor, a noção de gramática política é "a existência de diferentes combinações culturais e elementos dentro de uma mesma estrutura". (NUNES, 1997, p. 44) Trata-se, assim, do "conjunto de regras mais ou menos tácitas e consensuais de concepções e de práticas políticas, que foi se constituindo historicamente como tal". (BONETTI; FONTOURA; MARINS, 2009, p. 20) 
a lado, hip-hop e feminismo. Ambos compartilham sua origem e trajetória vinculada a "coisas do estrangeiro", o que remete à relação de apropriação pela juventude feminista e negra dos dois movimentos, que compartilham uma referência vinda do exterior, mais especificamente Estados Unidos e da Europa.

Questiona-se, por ambos terem origem no exterior, se tiveram o mesmo tipo de recepção ao aportarem no Brasil e na Bahia pela juventude soteropolitana. Como esses movimentos e suas respectivas ideologias foram apropriadas pelo segmento jovem do movimento social soteropolitano? Essas são algumas questões que envolvem o contexto estudado e que podem ilustrar o entendimento das hip hoppers soteropolitanas sobre a relação entre hip-hop e feminismo. É o que explica a rapper Negramone,

Porque existe a palavra feminista, e se a gente pega só a construção dessa palavra, ela vem de uma outra localidade, de um outro universo de uma outra realidade. Então não é um 'feminista', vamos dizer que é um feminista local, que dialoga como o nacional, o internacional, entende? Esse feminista local a gente pode se dizer que a gente, enquanto juventude, enquanto mulheres, ele existe, mas de uma forma de que como a gente pensa o feminismo, entendendo as suas diversidades, entendendo os seus propósitos e encaixando as nossas sugestões, os nossos objetivos, como a gente quer o feminismo. Não é universal, é como o Hip-hop. O movimento Hip-hop não é universal dentro de uma política de justiça social, racial. Ele existe em suas diversidades, ele tem as suas outras vertentes de filosofia assim como o feminismo, entende? Por isso que gente vai direcionando pra aquele feminismo local, aquele movimento local, mas dialogando com essa diversidade nacional e internacional e entendendo essa diversidade. Porque cada lugar é diferente, por mais que seja a mesma periferia, mas a periferia é diferente, 
cada um tem os seus problemas, cada uma tem a suas questões, violências, cada uma tem o seu jeito de viver.

A rapper aponta diversas questões relevantes em sua fala que ilustram o seu entendimento sobre esses dois movimentos. A primeira se refere ao reconhecimento de um feminismo que está localizado, tem demandas específicas ligadas à realidade de uma juventude que vivencia os problemas de sua cidade e bairro, mas que, ao mesmo tempo, compartilha questões das mulheres de outras localidades. Assim, também foi apontada a mesma característica ao hip-hop, pois ele também pode vir de fora e incorporar questões de outros lugares. Apesar disso, ambos se adaptaram à realidade local da comunidade em que se inserem sob uma motivação e interesse de luta por justiça social, mesmo diante das diferentes vertentes que possam apresentar.

Um importante aspecto a ser considerado é a discussão em torno da origem ou mesmo surgimento e trajetória do hip-hop, como demonstrado anteriormente, que tem se apresentado frequentemente nos diversos segmentos do movimento soteropolitano, como se pode perceber na fala das hip hoppers. Alguns militantes avaliam o conhecimento da história do hip-hop, seja nos Estados Unidos ou no Brasil, como critério para distinção entre militantes e artistas vinculadas a algum elemento "avulso" do movimento.

Esse interesse na história do hip-hop suscita algumas questões. O fomento ao conhecimento acerca das experiências da população negra da África à Diáspora, inclusive sobre os movimentos negros e suas lideranças, especialmente nos Estados Unidos e no Brasil; e o estímulo a uma formação política e à militância embasada nesta história social e nas atualidades apontam para a necessidade de maiores informações sobre os outros movimentos que dele se aproximem. É o que Eliciana coloca quando fala que "a história que 
a gente conhece aqui do Hip-Hop, que a gente aceita é essa, que o Hip-Hop, ele surge como um elemento politico, de resolver os conflitos sociais".

Segundo Eliciana, nos Estados Unidos o Hip-hop não é mais reconhecido dessa maneira politizada, pois atualmente carrega uma conotação muito comercial, distinta da luta por cidadania com qual os movimentos sociais estão comprometidos. ${ }^{83}$ Para ela, a versão defendida pelo movimento soteropolitano é a de receber algo que é fora, do "estrangeiro", porém essa versão também carrega uma conotação vinculada a uma herança negra:

A gente acredita em uma filosofia de hip-hop daqui, a gente alimenta isso o tempo todo, porque a gente reconhece a história do movimento Hip-hop desde a África, do nascimento do Griôs, da transição pros Estados Unidos por conta das guerras que aconteciam na África, da união dos quatro elementos lá e da propagação dele no mundo e até a chegada dele aqui no Brasil.

Essa interpretação exposta por Eliciana traduz a versão defendida pelo movimento soteropolitano que compreende o hip-hop como uma herança africana, baseado na cultura griô, a qual atuava com elementos artísticos para trabalhar a educação com jovens e adultos. Com o processo de diáspora da população negra, tanto seus elementos como o conhecimento em torno da cultura africana se dissipam pelo mundo. A rapper Paula escreveu sobre a relação do hip-hop e de seus elementos com a educação de jovens em sua graduação em Pedagogia, e resume qual é a sua preocupação e a do movimento em relação à história do hip-hop:

Sei, porque como integrante do movimento, primeiramente, eu sempre, eu sei que é necessário que a gente

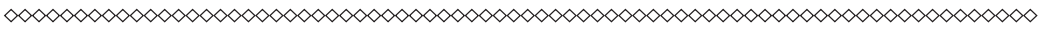

83 Durante a experiência do intercâmbio nos Estados Unidos citada anteriormente, pude perceber o incômodo que o hip-hop, e mais especificamente o rap, causava nas pessoas, o que me reteu de imediato à sensação vivenciada no Brasil em relação ao estilo do pagode com suas músicas e danças polêmicas. 
tenha essas informações, a gente não vai lutar por um movimento, está em um movimento sem saber como é que ele começou, as origens, onde ele está hoje, pra onde ele está se encaminhado.

É dessa forma crítica que esse movimento é construído pelas jovens hip hoppers, pois através dele promovem uma releitura acerca de sua própria realidade. Dessa mesma forma crítica e antenada essa juventude transforma e constrói seu próprio feminismo com a linguagem do hip-hop. É interessante perceber as oportunidades que uniram esses movimentos como em um processo social, num campo propício para criações de espaços de trocas de conhecimento. Esse diálogo entre os campos do feminismo e do hip-hop potencializou as mulheres em seus movimentos, como mostra Carla em sua experiência com os elementos do hip-hop:

A música e o break: eu acho que é muito palavra e corpo. Através do ra, justamente por conta de eu estar inserida no meio e de amizades mesmo, né, pra me apresentar esse mundo do rap, da música é... eu enquanto sujeita, no caso. Não enquanto uma pessoa que fica sentada ouvindo rap e tal; mas aí as amizades vêm no sentido de é... de eu poder me expressar também através da música, né. Eu também posso fazer música, eu também posso cantar né. E através do break, porque dentro dessa, desse espaço de militância do movimento Hip-hop né,e aí vem a discussão de gênero que a gente percebe que as mulheres, mesmo sendo um espaço de lutar contra a opressão, um espaço de resistência, como eu já falei, mas é um espaço também que reproduz muita coisa e aí a gente é, é... pesa muito sobre essa questão do corpo, como esse corpo se movimenta, como esse corpo fala também e o break eu tive contato a partir do, de um curso de formação né, formação de b-girl. 
O caso de Carla, em meio a atividades de desenvolvimento dos elementos do hip-hop, do rap e do break, mostra o movimento Hip-hop aberto para tratar de questões variadas, porém situadas e inseridas em um espaço político, "sendo um espaço de lutar contra a opressão, um espaço de resistência". Entretanto, como observação comum a todos os movimentos sociais, Carla afirma que mesmo com todo o caráter político contestatório das convenções sociais e de gênero embutido ao hip-hop, este "é um espaço também que reproduz muita coisa”. É um movimento que protesta contra as desigualdades e discriminações, mas também é um espaço em que essas violências acontecem, o que expõe o desafio posto ao próprio movimento, ponto de constantes críticas das hip hoppers.

Contudo, quando a pauta é o corpo, o diálogo entre o hip-hop e o feminismo se encontra nas formas de andar, vestir, falar, pintar e dançar. O hip-hop e o feminismo são capazes de tratar sobre múltiplas questões de movimento do corpo das mulheres e das convenções nas quais está envolto. Afirma Carla que "pesa muito sobre essa questão do corpo, como esse corpo se movimenta, como esse corpo fala também". O corpo é lido por essas jovens sob outra linguagem, que sofre interferências desta militância hip-hop e feminista ou de mulheres. Quando questionada como uma hip hopper percebe a interferência do movimento social em sua vida, seja ele o hip-hop ou feminismo, Negramone responde:

Interferem porque muda o corpo dessa pessoa, muda o estilo dessa pessoa, muda e acaba identificando pra essa pessoa quem ela é, de onde ela veio, a história dela que nunca foi contada. Influencia porque acaba sendo um conceito muito, como vou dizer, conceito conjunto e partindo dessas experiências que essa pessoa é, ela acaba sendo referência. Eu não gosto muito da palavra in- 
fluenciar, de influenciado. Gosto de palavras que possam suscitar, vamos dizer, referências. Porque quando uma criança vê sempre a televisão e vê sempre personagens de desenho brancos, elas vão querer ser, a referência pra ela é ser branca. Então, eu vou num conceito de referência, então as pessoas se sentem dentro das suas casas, elas se vêem, se vêem como pessoas políticas, como pessoas dinâmicas, como pessoas que podem construir uma nova sociedade, podem transformar onde vive, e podem falar porque a sociedade precisa disso, os jovens, na verdade, precisam disso e o hip-hop suscita essa lógica de você falar, de você falar das coisas que nunca foram colocadas pra você se manifestar, entendeu? Então, vai muito, muito mais direcionado pra isso. Pra essa essência mesmo da mulher, da mulher negra, do homem branco, do homem branco no sentido dele até se autoafirmar também, dentro dessa própria articulação, e pra saber de como racismo funciona, de como sexismo, de como o machismo funcionam. Contribui? Contribui pelo ser, acho que, contribui não... Acho que ainda contribui... Não só contribuiu pra algumas coisas, e contribui pra... Contribuiu pra eu ser a pessoa que sou hoje, por saber o contexto da minha realidade, de que estado eu vivo, de que país é esse e contribuiu pra eu entender que nem tudo que a gente vê é o que é.

A interferência dos conhecimentos adquiridos na experiência de militância no movimento social é responsável por transformações na visão de mundo dessas jovens, porque " muda o estilo dessa pessoa, muda e acaba identificando pra essa pessoa quem ela é". (Negramone) Essas ideias de autoconhecimento do indivíduo, de assumir sua identidade, de se reconhecer ou se sentir representada por alguém, e o reconhecimento de seu próprio poder de transformação da sociedade onde se vive são resultados 
de um processo de politização e empoderamento dessas jovens que "se veem como pessoas políticas, como pessoas dinâmicas, como pessoas que podem construir uma nova sociedade". (Negramone)

Conforme afirma Negramone em seu depoimento, "o Hip-hop suscita essa lógica de vocêfalar, de você falar das coisas que nunca foram colocadas pra você se manifestar", ou seja, o movimento se apresenta como um estímulo à reflexão, provocando as mulheres a pensarem sobre si mesmas, sobre o lugar onde moram, a situação do transporte de sua cidade, a lógica de beleza da mídia ou qualquer outro assunto sobre o mundo à sua volta. Elas são convidadas a se situarem, a terem uma opinião e conhecerem um pouco mais sobre elas mesmas, ao mesmo tempo em que esse conhecimento interfere no reconhecimento de suas referências: "Contribuiu pra eu ser a pessoa que sou hoje, por saber o contexto da minha realidade”. Diante dessa contextualização do possível diálogo entre hip-hop e feminismo, essa jovem apresenta subsídios para pensar acerca de um novo segmento dos movimentos sociais feministas e do hip-hop.

\section{Hip-hop feminista}

Em resposta à pergunta: "Você acha que é possível um hip-hop feminista?", as entrevistadas se surpreenderam com a expressão utilizada, o que foi recebido como uma reação inusitada. Depois, foi considerado que até o momento eu, como pesquisadora, não tinha referência de tal expressão no trabalho de campo ou na literatura. Como resultado da questão, a maioria das entrevistadas, exceto uma delas, acredita que seja possível ou mesmo que já exista esse hip-hop feminista.

De acordo com Negramone, este poder de transformação se traduz em criação quando ela explica que "Eu acho que é possível 
um hip-hop feminista, um hip-hop masculinista, um hip-hop indígena, acho que somos seres humanos e temos todas as possibilidades de criar". Para justificar a construção desse tipo de hip-hop e de feminismo, Carla se baseia em sua identidade racial e questiona se esse feminismo apenas seja possível e de interesse das e para as mulheres.

Sim. Hip-hop feminista, que bonito. Eu acho que é possivel sim um hip-hop feminista e eu acho que a gente faz isso né, acho que o grupo que faço parte tem essa/ Leva um pouco essa ideia do hip-hop feminista, que a gente questiona muito esses papéis da questão de gênero, né? Também dentro da nossa música e aí pegando o que eu falei, questão de gênero e de raça muito e a nossa sobrevivência mesmo enquanto mulheres né, mulheres negras. Eu acho que é, é/ Eu já vivo num hip-hop feminista, né? A gente espera que não seja só, só praticado por homens, mas que o hip-hop feminista seja praticado por/ Não. Não só por mulheres, mas que também seja praticado pelos homens, o hip-hop feminista, que eu acho que isso ai ta longe, mas é possivel, a gente acredita nisso.

Como informa a rapper, esse hip-hop feminista é identificado como referência para o grupo do qual participa, no caso, a banda de rap Munegrale. É Dina que, não apenas responde a questão colocada, como a justifica e exemplifica as expressões possíveis deste hip-hop feminista na atuação das militantes nos elementos artísticos do movimento.

PESQUISADORA: E tu achas que é possivel um feminismo, um hip-hop feminista?

DINA: Não só é possível como já existe, já existe. 
PESQUISADORA: Fala um pouquinho desse hip-hop feminista.

DINA: É quando as meninas pegam o microfone, são feministas, é quando a menina vai pro grafite, quando a menina diz que coisas de menino também são coisas de menina. Agora os meninos precisam saber que coisa de menina também é coisa de menino, agora nós já sabemos que coisa de menino é coisa de menina também, então é por isso que a gente faz, que algumas meninas têm feito, eu não digo tanto eu agora, mas já fiz a minha parte e as meninas estão dando continuidade.

Quanto à relação dos hip hoppers homens com esse tipo de hip-hop, será dada atenção em seção posterior, devido a não apenas ser um tema frequente nas falas das hip hoppers, mas também por faz parte de uma classificação e de questões sobre os hip hoppers, de acordo com suas posturas em relação às mulheres e ao feminismo. Apenas uma das entrevistadas respondeu de forma negativa à possibilidade de um hip-hop feminista. Ela explica o motivo para sua discordância baseada na experiência de outro movimento. Vivian responde:

Eu acredito que não. Porque assim é... o movimento negro tá aí com suas... vários buracos que aconteceram e dentro do movimento do MNU mesmo, de onde eu vim também, de onde eu venho, tem as mulheres feministas que acabaram criando um movimento dentro do movimento negro, hoje em dia elas não são mais do MNU, por essa conta. [...] De uma geração que vem do $M N U$, que elas criaram o movimento feminista lá dentro e que acabou com esse resultado, e uma coisa que o Hip-hop mesmo não quer, que são mulheres fazerem outro movimento ali dentro. Eu acredito que seja mulheres pra estar lutan- 
do igual a igual [...] Eu quero que cheguem mais mulheres e que a gente tenha autonomia de ficar igual a igual, de botar, pegar, fazer um show de rap, [...] e eu quero que seja igual pra igual sem... como me chamar de 'cara', levantar a mão e dizer eu sou 'cara' não, eu sou moça, mas que precisa criar outro... E que ele se reeduquem né! Eu acredito muito nisso.

Há uma preocupação de que o feminismo separe os grupos constituídos por homens e mulheres, como relato do ocorrido em outro grupo do movimento negro, o que aponta que existem problemas a serem discutidos. Contudo, para melhor compreender acerca desse "hip- hop feminista" procurei aprofundar o conhecimento acerca das concepções de feminismos construídas pelas jovens mulheres militantes, concepções essas que as orientam e estão sendo (re)produzidas em suas práticas políticas.

\section{Hip-hop feminista e suas concepções de feminismos}

Na pesquisa de campo em Salvador, as noções sobre feminismo apontaram para uma politização para além do comportamento ou estilos de se vestir das hip hoppers. Com a mesma forma crítica que se envolveram com o hip-hop, essas jovens veem o feminismo como um conjunto de discussões em torno dos aspectos de classe, raça e sexualidade, que mapeiam a própria história das mulheres e a história do feminismo.

O que as hip hoppers soteropolitanas definem por feminismo? Dentro disso, elas se colocam como feministas? Que tipos de feminismos podem ser identificados em suas falas? E quais são as questões centrais que as motivam ou as fazem rechaçar, ou mesmo ressignificar o feminismo? Na busca por conhecer as concepções sobre o feminismo que embasa esse hip-hop feminista, nas falas 
das hip hoppers foram identificadas três relevantes questões: 1) Da sexualidade e autonomia das mulheres; 2) Da raça e da classe; e 3) $\mathrm{Da}$ (des)substancialização do feminismo em relação às mulheres.

\section{Da sexualidade ${ }^{84}$ e do corpo das mulheres}

O feminismo traz consigo a história da luta das mulheres no mundo, sendo compreendido como um movimento que defende os direitos das mulheres. Além de ser visto como uma forma de vida que orienta diferentes possíveis visões de mundo, o feminismo também se dedica à própria relação das mulheres com o seu corpo. Negramone explica sua posição acerca dessas questões:

Eu entendo feminismo como uma política transversal, uma política em que discute a questão da mulher, a questão racial, a questão, vamos dizer, de estado também e da questão da sexualidade como um todo. Então eu entendo como uma filosofia de vida, como uma filosofia de vida e de vida mesmo dessas mulheres [...]. As dificuldades são muito universal, principalmente, quando se toca na questão de ser mulher, jovem, negra e por ter orientação sexual afetiva diferente da norma, são vastas, então, sóo fato você ter essa dificuldade dos próprios, vamos dizer, companheiros de movimento, os próprios companheiros de movimento não deixar que você possa realizar uma coisa que vai ser interessante para o próprio movimento nessas discussões de gênero, nas questões da masculinidade dos homens dentro do movimento, na construção de uma sociedade menos sexista, machista, homofóbica.



84 Segundo Jeffrey Weeks (2000, p. 25), "a sexualidade tem a ver com nossas crenças, ideologias e imaginações tanto quanto com o nosso corpo físico". 0 autor continua sua exposição do tema afirmando que "os corpos não têm nenhum sentido intrínseco e que a melhor maneira de compreender a sexualidade é como um 'cons-truct-histórico'”. (WEEKS, 2000, p. 25) Nesse sentido, a sexualidade está para além do corpo, estando situada ao contexto histórico e cultural de cada indivíduo, a exemplo das jovens hip hoppers soteropolitanas, que trazem consigo sua bagagem social expressa em seu corpo. 
Para Negramone, feminismo é "uma política transversal", "uma filosofia de vida" que tem como prioridade as mulheres e que dialoga com as categorias que as identificam em sua identidade racial, sexual, entre outras que a rodeiam. Carla também contribui com esse debate quando afirma ser reduzido o número de mulheres no movimento em comparação com o número de homens. Em detrimento desse contexto, as mulheres são recepcionadas pelos homens no movimento, questionadas a partir de seus corpos, como relata Carla: "o primeiro olhar da dúvida, duvidar do potencial da menina e o outro olhar que é tipo de seduzir mesmo aquela menina, acham que aquela menina é pra do lado deles que tá lá no movimento".

A $b$-girl Priscila destaca a autoestima e a confiança quando afirma que acredita que feminismo "é quando a gente cuida da gente, é quando a gente corre atrás de nossos objetivos, quando a gente luta por aquilo que a gente quer". É como se o feminismo pudesse impulsionar a força que cada mulher tem dentro se si para a realização de suas metas pessoais e profissionais. Já para Paula, feminismo é sinônimo de luta contra o machismo, termo utilizado pela rapper. Paula já dá indícios do debate sobre quem pode ser machista: homens e mulheres podem? Esse debate ficará para a seção posterior que tratará da (des)substancialização do feminismo de acordo com as hip hoppers.

Feminismo é o sistema que a gente criou pra se autodefender, não só dos homens, mas do sistema o machismo. Que a meu ver não tá somente integrado na relação homem - mulher, o machismo é uma coisa que já ta tão arraigada na sociedade que até uma mulher pode ser machista [...]. Como uma forma de luta, de busca de nós mulheres, cada uma com as suas realidades, a mulher negra com a sua, a mulher branca com a sua, a mulher indígena com a sua, cada uma com seu olhar, do seu ângulo continuando a luta. 
Dina concorda com Paula que o machismo atinge a todas as mulheres, independente de sua identidade étnico-racial. Por isso, ela defende o feminismo como a luta das mulheres pelo direito de decidir. Para ela, "feminismo é a busca por autonomia das mulheres, estas mulheres brancas, mulheres negras e mulheres indígenas, é autonomia, a luta dessa autonomia, isso é ser feminista, eu entendo por â". ${ }^{85}$ Dina é questionada se ela se considera feminista e responde: "Sim, lógico, eu sou uma feminista negra, lógico que sim”. Essa afirmação nos leva à próxima questão sobre o diálogo do feminismo com as questões de raça e classe discutidas pelas hip hoppers.

\section{Da raça ${ }^{86}$ e da classe ${ }^{87}$}

A questão colocada sobre um "feminismo negro" como referência para as hip hoppers foi muito recorrente nas atividades e conversas desse movimento de mulheres. Contraposto a um movimento de mulheres brancas e de classe média, o feminismo negro apresenta-se como uma polêmica, pois tem base na pluralidade dos feminismos e das experiências das mulheres.

Os movimentos sociais e os lugares de fala dessas jovens devem ser compreendidos para explicar as bases que orientam os seus pensamentos acerca do feminismo negro. Para tanto, Paula faz uma distinção do feminismo em relação a mulheres negras e mulheres brancas, tendo como base a situação de classe. Ela aponta um caso que se embasa na discussão em torno da possibilidade de um compartilhamento de responsabilidades quanto à divisão de tarefas domésticas por um casal.

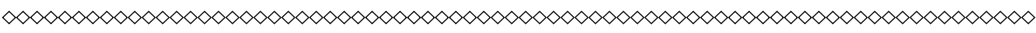

85 Fala da entrevistada Paula.

86 Raça é aqui entendida como política que remete à identidade constituída a partir dos aspectos que ligam o pertencimento a um grupo histórico não apenas pela cor da pele e fenótipo, mas também pela autoafirmação e resgate da ancestralidade.

87

Classe compreende um extrato social que se baseia na média de renda econômica compartilhada por um grupo, o que também abrange aspectos como estilo de vida e visão de mundo. 
Porque a gente tem uma visão do feminismo sobre a ótica branca de fazer feminismo. 'Ah! Eu sou feminista porque eu não cozinho, porque eu não vou lavar cueca de ninguém, porque eu não vou varrer a casa, porque eu tenho que ir pro trabalho', não é isso. Eu acho que enquanto mulher, eu não faço isso por que eu sou mulher, faço isso porque eu acho legal, cuidar do meu marido eu acho legal, varrer a casa eu acho legal, eu acho legal lavar os pratos, eu acho legal enfeitar a casa. E ele também faz a mesma coisa.

A distinção já se apresenta na visão de que trabalho doméstico reuniria tarefas negativas a serem feitas e compartilhadas por um casal. A ideia da rapper procura desassociar uma divisão sexual do trabalho, bastante questionada pelo feminismo, de uma divisão de tarefas em que as mulheres são sobrecarregadas com a exclusividade de responsabilidade com as tarefas do lar, como lavar, passar, arrumar a casa etc. Entretanto, ela interpreta negativamente as reivindicações do feminismo a partir de um maniqueísmo entre brancas/negras e pobres/ricas, ao tratar as mulheres brancas como que excluídas da realidade dessa sobrecarga de tarefas, pois o feminismo dito como "branco", para ela, se nega à realização de tais funções próprias da dinâmica de uma casa, especialmente por compreender esse feminismo por um veio de representação de uma classe dominante, o que não é exatamente tão preestabelecido desta forma na sociedade.

Carla também contribui com esse debate quando destaca a distinção de sua compreensão sobre a história do feminismo, ao pensar a trajetória e experiências das mulheres brancas europeias e as mulheres negras brasileiras desde o período da escravidão no país:

Entendo por feminismo uma forma coletiva de se lutar por direitos iguais entre homens e mulheres. Entendo 
feminismo também não só a história do feminismo da Europa, mas a história do feminismo de como se configurou aqui entre as mulheres negras também, no Brasil. E ai vem a discussão de que se é movimento de mulher ou feminismo? Acredito, por exemplo, que as irmandades que existiam aqui, que lutavam e juntavam dinheiro pra comprar alforria do escravo, eu entendo isso como feminismo. Essas mulheres organizadas em prol de uma causa assim, eu entendo como feminismo.

Pode-se afirmar que essa crítica racial e de classe em torno de um feminismo de referência branca e europeu se apresenta fortemente entre as hip hoppers soteropolitanas. Diante de referências de mulheres brancas e de classes que tiveram um acesso a maior escolaridade, esse feminismo é reconhecido como algo “intelectual”, e branco. É um dos aspectos que difere das próprias experiências das mulheres negras, que historicamente tiveram menos oportunidades de acesso ao ensino e, consequentemente, menos oportunidade de registros intelectuais de suas próprias experiências.

Quando questionadas sobre seu entendimento do feminismo, as hip hoppers logo se remeteram à ideia de estudos, escritas, algo da academia, tendo este como um conhecimento registrado e também como uma forma de contato com esse pensamento. Essa vinculação do feminismo à leitura conota ligação com uma classe que teve acesso à educação e a uma maior escolaridade, no caso, as mulheres que produziram registros escritos sobre suas experiências sob uma perspectiva crítica das relações de poder é que seriam as feministas. Entretanto, essas questões apresentam-se como ambivalentes diante de uma demanda do próprio movimento Hip-hop com relação à preocupação com acesso à educação e ao conhecimento, bandeiras que podem ser exemplificadas na luta por ações afirmativas no ensino superior e pela implementação da 
história e cultura africana e afro-brasileira nos currículos escolares. Mais uma vez, a questão de classe pode ser identificada diante do entendimento às críticas das hip hoppers ao feminismo:

PESQUISADORA: O que é feminismo para você?

ELICIANA: Mas assim, eu acho que é a rebeldia feminina de ser feminina e de lutar pelo direito de ser feminina, de ser mulher e de não deixar que o machismo tome conta se si mesma. E acho que alguma coisa assim da história do feminismo que eu me lembro é que, falando de revoluções de mulheres, assim, que aconteceram, uma coisa que eu sempre ouço é que enquanto as mulheres brancas estavam queimando sutiã, as mulheres negras estavam incendiando fazendas! Eu não sei se você já ouviu isso, já ouviu né!? Que é a coisa mais linda, mais forte que eu ouço, porque dentro dessa ideia de feminismo, o pouco que eu já li, já ouvi sobre feminismo, porque a gente sabe como é diferente ser mulher negra, ser mulher é foda, mas ser mulher negra é foda num sei quantas vezes! E a gente tem que ter uma rebeldia de feminista muito maior, muito maior.

Nos anos de 1970, ocorreu uma eclosão de movimentos em diversas partes do mundo sob o lema de reivindicações de direitos. Segundo Matilde Ribeiro (1995), é diante de um contexto de ditadura militar que o movimento Feminista ressurge no Brasil, com pautas que encabeçavam a vida particular e privada envolvendo temas como sexualidade, direito à creche para filhos e filhas de trabalhadores, liberdade sexual, além de igualdade salarial, representação política e políticas públicas para mulheres. Entretanto, a questão racial e das mulheres negras estava de fora. Época de eclosão, também, dos movimentos negros interessados na luta por cidadania no país no bojo das lutas antirracistas internacionais que 
marcaram a "década da mulher" pela ONU. A própria organização das mulheres negras apenas se efetiva em meados dos anos de 1980 no país, priorizando questões em torno de uma tríplice militância, que incidiam no combate à discriminação das mulheres negras e pobres.

As pautas desse movimento abarcavam pontos como: combate aos estereótipos que estigmatizam as mulheres negras; inserção no mercado de trabalho com o questionamento ao tratamento diferenciado de oportunidades e salários entre mulheres negras e brancas, regulamentação do trabalho doméstico, entre outros. Esse argumento baseia a fala de Vivian:

Assim, eu não [pausa] eu posso dizer assim: eu nunca me adaptei muito em ler sobre o que é feminismo, porque eu tinha muita resistência por dizer que é um movimento de mulheres brancas, eu não sou feminista, eu digo muito isso, eu sou feminina, porque desde adolescente vi que o movimento Feminista é um movimento de mulheres brancas, e aí então não me identifico, mas eu acho que é um movimento de mulheres que luta pela sua liberdade, pela... pelos direitos que elas tem na sociedade que por causa delas serem mulheres elas não tem.

Em sua fala, Vivian reativa a discussão da separação entre movimento Feminista e Movimento de Mulheres, ${ }^{88}$ debate que tem dado subsídio para a afirmação de um Movimento de Mulheres negras, mas sem um consenso em torno da questão. Já Carla agita mais esse debate quando aponta um Movimento de Mulheres negras e feministas.

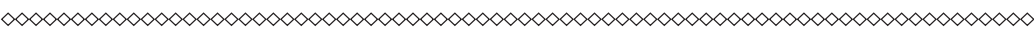

88 Para as autoras Ana Alice Costa e Cecilia Sardenberg (1994), o que distingue o movimento Feminista do Movimento de Mulheres é justamente a estruturação em torno da doutrina feminista e o questionamento da situação das mulheres na sociedade, e não apenas pela simples reunião de mulheres por questões específicas, que não incidam diretamente no reconhecimento ou transformação do lugar onde elas se encontram. 
A luta por igualdade e também a luta pela sobrevivência. Sobrevivência das mulheres e das suas famílias. Que aí eu me remeto muito ao movimento de como as mulheres negras que vieram pro Brasil se organizaram e tentaram sobreviver, mas aí pensando não só na sobrevivência dela, mas pensando na sobrevivência dos filhos, dos maridos também. Eu entendo isso como feminismo, mas não só por mulheres, mas que também seja praticado pelos homens, o hip-hop feminista, que eu acho que isso aí está longe, mas é possível, a gente acredita nisso.

O feminismo reconhecido como combate às desigualdades entre homens e mulheres aparece como possível estratégia de luta contra o machismo, a ser construída por homens e mulheres. Mas o feminismo é para homens e mulheres? Ambos podem se afirmar feministas? Essas questões nos levam para nossa última seção.

\section{Da (des)substancialização do feminismo}

Uma das concepções de feminismos encontradas nas falas das hip hoppers envolvia questões como: homens e mulheres feministas e machistas e feminismo para os homens a partir das suas experiências dentro do movimento. Questões essas que promoveram uma espécie de (des)substancialização do feminismo.

A relação entre homens e feminismo foi um tema vigente em falas como a de Carla: "Não só por mulheres, mas que também seja praticado pelos homens, o hip-hop feminista, que eu acho que isso aí está longe, mas é possível, a gente acredita nisso!". O combate contra a opressão às mulheres aparece como uma alternativa aos homens, também responsáveis por essa transformação social construída pelo que seria esse hip-hop feminista. É o que Paula coloca: "É possível, é real, ele já existe. A gente faz, nós somos mulheres e feministas, não feministas porque somos mulheres, mas somos mulheres feministas, como tem homens 
feministas também”. A rapper faz uma distinção entre ser feminista e ser mulher e abriu uma discussão polêmica entre as próprias feministas, a qual gira em torno dos homens feministas.

Pode haver homens feministas e mulheres machistas? Para Paula, "o machismo é uma coisa que já está tão arraigada na sociedade que até uma mulher pode ser machista". O hip- hop reconhece que este sistema de valores "machista" pode ser alterado diante de uma meta que objetiva uma (re)educação para homens e mulheres.

Totalmente, hoje com o ideal de ter uma organização que seja autossustentável, que faça a gente se autogerir, é muito mais um desejo de conseguir desenvolver os trabalhos com esse público, com essas mulheres, com esses homens também, os homens precisam de uma atenção no sentido de se (re)educarem [risos]. Meu objetivo é fazer esse movimento ser grande, que ele já é. Mas, sei lá, ser mais uma pessoa que chegou pra, que chegou que tá chegando, que tá indo, que tá se instrumentalizando pra fazer o movimento da gente crescer, se fortalecer e continuar ser diferente do movimento estadunidense que é vendido na mídia.

Essa é a preocupação em manter o hip-hop como compromisso de transformação social, apontando para uma postura diferenciada deste movimento em relação ao que (re)produz discriminações e ao que está "vendido na mídia". Este hip-hop feminista seria possível de educar homens para o feminismo. Embora os hip hoppers não tenham sido entrevistados, não é comum ver homens se colocando como feministas. Porém, segundo Paula "Conheço alguns homens feministas, o meu parceiro é feminista. Ele me cobra o tempo inteiro que eu não me atenta às atitudes machistas, ele é feminista. Têm outros, outros parceiros, 
vários outros". Já Dina é mais comedida e afirma que "nós temos homens que são sensíveis à nossa causa, nós temos poucos".

A necessidade de uma nova perspectiva de ação para homens no hip-hop perpassa por uma nova forma de olhar sobre o machismo, de acordo com Eliciana. Pode ocorrer que, o que os homens acham que seja colaboração e parceria para com as mulheres, não seja exatamente isso.

Assim, eu acho que, sei lá, tem muita coisa pra avançar ainda, que vai desde as letras de música, da tentativa que eu vejo dos caras de tentar fazer alguma coisa pras mulheres, mas que porra, eu já vi coisas assim de que, por velho, fique calado, não fale isso não, não tenta ajudar a gente não porque você tá prejudicando, deles tentarem, tipo: 'Ah, eu sou o cara que estou do lado das mulheres, mas olha o que eu estou falando!'.

Esses foram alguns dos temas que se destacaram em campo e que são desafios em contínuo embate dentro da militância no hip-hop, no que se refere às convenções de gênero e feminismo nesse movimento. Essa juventude sabe que esta é uma luta constante contra as discriminações, em suas várias faces. Contudo, o que essas jovens têm construído como "hip-hop feminista" une movimentos feministas e de mulheres, movimentos negros e movimentos jovens, e se constitui um instrumento possível para contribuir com essa transformação social, por ser contestatório das desigualdades, especialmente em relação às mulheres. É o que se resume e se conclui na fala de Dina quando ela responde sobre as expectativas para o futuro:

Ah, são tantas, minhas expectativas é que realmente o MHH assim como outros movimentos que eu faço parte, eles realmente comecem a mudar na sua total, mudar mesmo, mudar em que sentido, assim, principalmente 
em relação a nós, mulheres, que os homens comecem, a maioria dos homens, que hoje nós temos homens que são sensíveis à nossa causa, nós temos poucos, mas eu acho que a minha expectativa é que daqui a um tempo todos os homens que venham a adentrar no MHH eles percebam que para ele estar ali dentro, ele precisa ter uma relação de gênero resolvida na cabeça dele, precisa entender essa relação para mudar entendeu, então essa é a minha expectativa, não entre no hip-hop porque 'ah, agora eu sou rapper', não, não, eu sou rapper porque eu quero fazer algo diferente, a minha relação com as mulheres vai mudar, porque eu entendo que esse movimento me propicia isso entendeu?

As hip hoppers construíram esse hip-hop feminista para empoderarem a si mesmas e às suas ações no movimento social, enquanto adentram nesse espaço político e inserem sua pauta. Pauta essa que está vinculada à contestação das convenções de gênero que geram as normas sociais em torno do masculino e do feminino, e orientam as próprias relações sociais vivenciadas por essas jovens, as quais desejam mudanças.

\section{Considerações finais}

O movimento de mulheres hip hoppers soteropolitano esteve no centro desta pesquisa, a qual investigou as convenções de gênero e feminismos nesse movimento social. Voz dos discriminados por denunciar as desigualdades sociais em torno das realidades dos grupos de jovens negros pelo mundo, o hip-hop também contesta as convenções de gênero em torno do masculino e feminino, ao passo que se transforma em um instrumento de luta e espaço de atuação das mulheres. 
A militância dessas jovens foi analisada a partir do questionamento de que elas reforçavam ou ressignificavam as convenções de gênero no hip-hop. O objetivo foi o de compreender, segundo a formulação das interlocutoras, o que era "coisa de menina" e "coisa de menino" no hip-hop. A partir da atuação das jovens foram elencados inúmeros desafios para que elas adentrassem no espaço do movimento, que era tido, inicialmente, como um espaço majoritariamente formado por homens. Entretanto, o hip-hop continha uma "brecha" para atuação das mulheres, a qual permitiu não só a inserção dessas jovens em contato com suas artes de rua, mas também a oportunidade de influenciar em pautas, em ações e na própria configuração do hip-hop soteropolitano desde sua criação no ano de 1990.

Seus contatos com artes do hip-hop ocorreram por meio da socialização entre jovens, motivados por inquietações em torno de suas situações de classe e raça vivenciadas pela juventude negra e pobre de Salvador. O que era compartilhado por outras juventudes, a exemplo da juventude negra estadunidense, que inicia o movimento inspirada em sua realidade de exclusão e nos ensinamentos dos movimentos civis e black power em seu país.

Entretanto, o que permitiu a compreensão das jovens do hip-hop como um movimento de contestação das convenções de gênero foi sua apropriação de mais um movimento social. As lições dadas pelo movimento Feminista em relação ao combate às desigualdades que afligiram as mulheres fomentaram uma apropriação acerca desse pensamento, que configurou as concepções de feminismo que estão sendo (re)produzidas na prática política das jovens mulheres militantes do movimento Hip-hop soteropolitano.

Essas concepções de feminismos, somadas às pautas já instituídas do movimento, proporcionaram a existência de um hip-hop feminista local. Com o intuito de avançar em relação à compreensão da pluralidade do feminismo como movimento social, 
foram comparadas as formas de apropriação e adaptações, pelos sujeitos da pesquisa, dos discursos feministas e das formas de engajamento das hip hoppers. Essas questões foram apreendidas na tensão entre suas concepções e suas práticas cotidianas relativas às demandas do movimento Hip-hop, bem como no papel desempenhado pela articulação entre os marcadores de gênero, sexualidade e raça na militância.

Como resultados encontrados, os principais argumentos que formataram esses discursos analisados das interlocutoras parceiras da pesquisa com base na crítica sobre uma concepção de um feminismo visto como branco e de referência europeia, tido como mantenedor das desigualdades entre as mulheres de diferentes classes e raças. Em sua militância, as hip hoppers desafiam e (re)significam os movimentos feministas com os quais estão em diálogo quando apreendem o feminismo, compreendido como a luta pela autonomia da sexualidade das mulheres, mas escolhem a referência dos feminismos que traduzem as experiências das mulheres negras, pobres e trabalhadoras.

A partir de suas concepções de feminismo, essas jovens construíram a possibilidade de um hip-hop feminista a partir da reflexão de três vertentes dos movimentos sociais: movimento Feminista, movimento Negro e movimento da Juventude. Nas falas das interlocutoras surgiram questões em torno de uma (des)substancialização do feminismo, devido ao questionamento acerca da essencialização da relação mulher-feminismo, especialmente por considerações acerca da postura dos homens no movimento, os quais foram classificados de três diferentes formas: homens machistas, homens sensíveis à causa dos direitos das mulheres, e homens feministas.

Dessa discussão, o que vale ressaltar é a responsabilidade que esse movimento assume com relação à transformação social no diálogo entre cultura e política voltado para a juventude. 
Conclui-se que, como um movimento social, o Hip-hop dialoga com a cultura política local ao mesmo tempo em que a desafia, ao definir pautas e estratégias políticas de reivindicação de direitos e de combate às desigualdades em geral e de gênero em particular.

A maior dificuldade ainda hoje é a lógica machista, a lógica machista de funcionar as coisas. Porque o machismo ele nunca me atingiu, ele nunca me atingiu, porque o machismo não atingir mulheres como nós, porque a gente sabe lidar com ele, ou aprendeu a lidar e o objetivo da gente que outras mulheres saibam, aprendam a lidar também com o machismo. Mas dentro do hip-hop o que me incomoda e o que me deixa mais... O que me preocupa é a lógica machista de funcionar, porque a todo tempo por mais que a gente esteja ali, mulheres na luta, conseguindo coisas e conquistando coisas, as barreiras elas sempre... elas permanecem. Parece que a cada vez que a gente fica mais forte, mais forte os muros são, os tijolos do machismo são cada vez mais empilhados, mais forte, eles usam um cimento mais forte, uma coisa mais impermeável. E aí a gente tem que ganhar outras habilidades, hoje eu estou no rap, amanhã eu posso dançar break e depois eu posso tocar disco e depois eu posso grafitar e depois eu posso... enfim, fazer, inventar um outro elemento, ou ter um outro elemento, entendeu, a gente tem sempre que se superar, esse é o maior desafio do hip-hop, que eu me sinto quando mulher no hip-hop. Porque a sociedade e o grupo onde a gente tá inserida sempre cobra mais da gente. E ver também que tem irmãs que não conseguem se superar, não consegue superar essa lógica e a gente pensa que ela tá indo, ela não tá indo, ela tá voltando. (PAULA) 
A relevância de conhecer a perspectiva das mulheres em suas experiências no Hip-hop soteropolitano registra a história do próprio movimento. Assim, é o hip-hop feminista soteropolitano mais uma das expressões que compõem a pluralidade dos movimentos feministas, o que aponta os desafios, as possibilidades e a criatividade dessas mulheres jovens negras de fazerem arte, bem como explorarem o campo do político. 